\title{
One complete and three draft genome sequences of four Brochothrix thermosphacta strains, CD 337, TAP 175, BSAS1 3 and EBP 3070
}

Nassima Illikoud ${ }^{1}$, Christophe Klopp ${ }^{2}$, Alain Roulet ${ }^{3}$, Olivier Bouchez ${ }^{3}$, Nathalie Marsaud ${ }^{4}$, Emmanuel Jaffrès ${ }^{1}$ and Monique Zagorec ${ }^{1 *}$

\begin{abstract}
Brochothrix thermosphacta is one of the dominant bacterial species associated with spoilage of chilled meat and seafood products through the production of various metabolites responsible for off-odors. However, metabolic pathways leading to meat and seafood spoilage are not all well known. The production of spoiling molecules seems to depend both on strains and on food matrix. Several B. thermosphacta genome sequences have been reported, all issued from meat isolates. Here, we report four genome sequences, one complete and three as drafts. The four B. thermosphacta strains CD 337, TAP 175, BSAS1 3, and EBP 3070 were isolated from different ecological niches (seafood or meat products either spoiled or not and bovine slaughterhouse). These strains known as phenotypically and genetically different were selected to represent intraspecies diversity. CD 337 genome is 2,594,337 bp long, complete and circular, containing 2593 protein coding sequences and 28 RNA genes. TAP 175, BSAS1 3, and EBP 3070 genomes are arranged in 57, 83, and 71 contigs, containing 2515, 2668, and 2611 protein-coding sequences, respectively. These genomes were compared with two other $B$. thermosphacta complete genome sequences. The main genome content differences between strains are phages, plasmids, restriction/ modification systems, and cell surface functions, suggesting a similar metabolic potential but a different niche adaptation capacity.
\end{abstract}

Keywords: Brochothrix thermosphacta, Listeriaceae, Spoilage, Chicken meat, Cooked shrimp, Bovine slaughterhouse, smoked salmon

\section{Introduction}

Brochothrix and Listeria are the only two genera belonging to the Listeriaceae family. Brochothrix thermosphacta is a non-pathogenic, psychrotrophic, and ubiquitous bacterial species. It is responsible for the spoilage of chilled meat and seafood products stored aerobically or under modified atmosphere or vacuum packaging. Spoilage of these foodstuffs by $B$. thermosphacta results from the production of volatile organic compounds (VOCs) responsible for off-odors. Two VOCs, 3-hydroxy-2-butanone (acetoin) and 2,3-butanedione (diacetyl) have been associated with both meat and

* Correspondence: monique.zagorec@oniris-nantes.fr

'UMR 1014 SECALIM, INRA, Oniris, Nantes, France

Full list of author information is available at the end of the article seafood products spoilage, whatever the packaging conditions [1]. We recently showed that the concentration of acetoin and diacetyl produced in beef or shrimp juices was strain and matrix dependent although the differences in the production level did not depend on the ecological origin of the strains [2]. The presence of other VOCs associated to the presence of $B$. thermosphacta in food depends on the food product (meat or seafood) and on the storage conditions [1]. Thus, it is yet unknown whether strains isolated from meat or from seafood have a similar spoilage potential and/or whether the food matrix or storage conditions can impact the expression of this potential. To date, 14 B. thermosphacta genome sequences, including two complete, are publicly available $[3,4]$. A comparative genomic analysis on

(c) The Author(s). 2018 Open Access This article is distributed under the terms of the Creative Commons Attribution 4.0 International License (http://creativecommons.org/licenses/by/4.0/), which permits unrestricted use, distribution, and 
12 B. thermosphacta draft genome sequences showed a high degree of similarity between strains and a similar gene repertoire for the production of several malodorous molecules [3]. Major gene repertoire differences among the genomes previously reported in the literature were characterized by phage related sequences $[3$, 4]. However, all were isolated from meat products and thus may not represent exhaustive $B$. thermosphacta diversity since this species has also been isolated from other ecological niches [5]. In addition, although $B$. thermosphacta has been reported to be involved in a wide variety of foodstuff spoilage, metabolic pathways responsible for most of the produced VOCs still remain unknown. In this study we chose four B. thermosphacta strains issued from diverse environments for a comparative genomic analysis. B. thermosphacta CD 337, TAP 175, EBP 3070, and BSAS1 3 were isolated from spoiled cooked and peeled shrimp, fresh chicken leg, spoiled smoked salmon, and from a bovine slaughterhouse environment (hide of a slaughtered animal), respectively [2]. These strains were chosen to represent a larger diversity than previously explored in genome comparisons. Indeed we previously showed that the four chosen strains are genotypically distant and have different abilities to produce acetoin and diacetyl [2]. Gene content of these four strains was compared to those of 14 available $B$. thermosphacta genome sequences in order to screen for potential features associated to specific niche adaptation or fitness, and for putative differences in their spoilage potential.

\section{Organism information}

\section{Classification and features}

B. thermosphacta CD 337, TAP 175, EBP 3070, and BSAS1 3 were isolated after plating on $B$. thermosphacta selective medium Streptomycin-thallous acetate-actidione (STAA, Oxoid) [6, 7]. Strains belonging to B. thermosphacta species were described as Gram positive, non-spore forming, and non-motile regular unbranched rods (Table 1). They are aerobe and facultative anaerobe, catalase positive and oxidase negative [5]. Gram staining and catalase reaction of freshly-grown cells of $B$. thermosphacta CD 337, TAP 175, EBP 3070, and BSAS1 3 confirmed all to be Gram positive and catalase positive [2]. Phylogenetic analyses based on $r p o B$ gene sequence alignments (Fig. 1) showed that B. thermosphacta strains CD 337, TAP 175, EBP 3070 and BSAS1 3 clustered within the Brochothrix genus. Based on these analyses, our four B. thermosphacta were also found to be closely related to Brochothrix campestris the only other species yet described in the Brochothrix genus and to Listeria monocytogenes.

Atomic force and scanning electron microscopies of fresh cultures showed that each strain population consisted mainly cells that were rod shaped with no flagella (Fig. 2).

\section{Extended feature descriptions}

The four strains were previously genetically and phenotypically characterized. These strains isolated from different ecological niches, belonged to different Rep-PCR, PFGE and MALDI-TOF clusters and present different abilities to produce diacetyl and acetoin in beef and cooked shrimp juices [2]. On the whole strain collection tested, CD 337 and BSAS1 3 were within the highest acetoin and diacetyl producers when grown in beef juice, and among the lowest after growth in cooked shrimp juice. Conversely TAP 175 and EBP 3070 produced the highest levels of acetoin and diacetyl in shrimp juice and the lowest ones after cultivation in beef juice [2].

\section{Genome sequencing information Genome project history}

In order to investigate $B$. thermosphacta species diversity, an initial study has been conducted on 159 isolates issued from various ecological niches. They were phenotyped on their ability to produce acetoin and diacetyl and were clustered, based on their genotypes (PFGE, Rep-PCR) and proteomic (MALDI-TOF) patterns [2]. Strains did not cluster based on their ecological origin nor on their spoilage compounds production ability. Therefore, to determine whether the spoilage potential of the strains was due to their gene repertoire and/or to the food matrix, we selected 4 strains, as diverse as possible, for a comparative genomic analysis. B. thermosphacta CD 337, TAP 175, BSAS1 3, and EBP 3070 have been isolated from a variety of food products and from environment. They have different abilities to produce spoiling molecules depending on the food matrix, and belong to different PFGE and Rep-PCR clusters [2]. Project information and associated MIGS are shown in Table 2.

\section{Growth conditions and genomic DNA preparation}

B. thermosphacta strains were grown overnight at $25{ }^{\circ} \mathrm{C}$ in $100 \mathrm{ml}$ Luria-Bertani Broth (Invitrogen) containing $10 \mathrm{~g} / \mathrm{l} \mathrm{NaCl}$. Cultures were shaken at $100 \mathrm{rpm}$. A cell pellet (about $2 \times 10^{10} \mathrm{CFU}$ ) was obtained by centrifugation at $5000 \times g$ for $10 \mathrm{~min}$. Genomic DNA was extracted using the Blood and Cell Culture DNA Midi Kit (Qiagen, France) according to the manufacturer's instructions for Gram positive bacteria with some modifications as previously described by [8]. Briefly, the cell pellet was resuspended in $3.5 \mathrm{ml}$ buffer B1 containing $0.2 \mathrm{mg} / \mathrm{ml}$ RNAse A. Bacterial cells were lysed by the addition of $220 \mathrm{mg}$ lysozyme powder (Euromedex, France) followed by incubation for $2 \mathrm{~h}$ at $37{ }^{\circ} \mathrm{C}$. High molecular weight genomic DNA was purified by gravity 


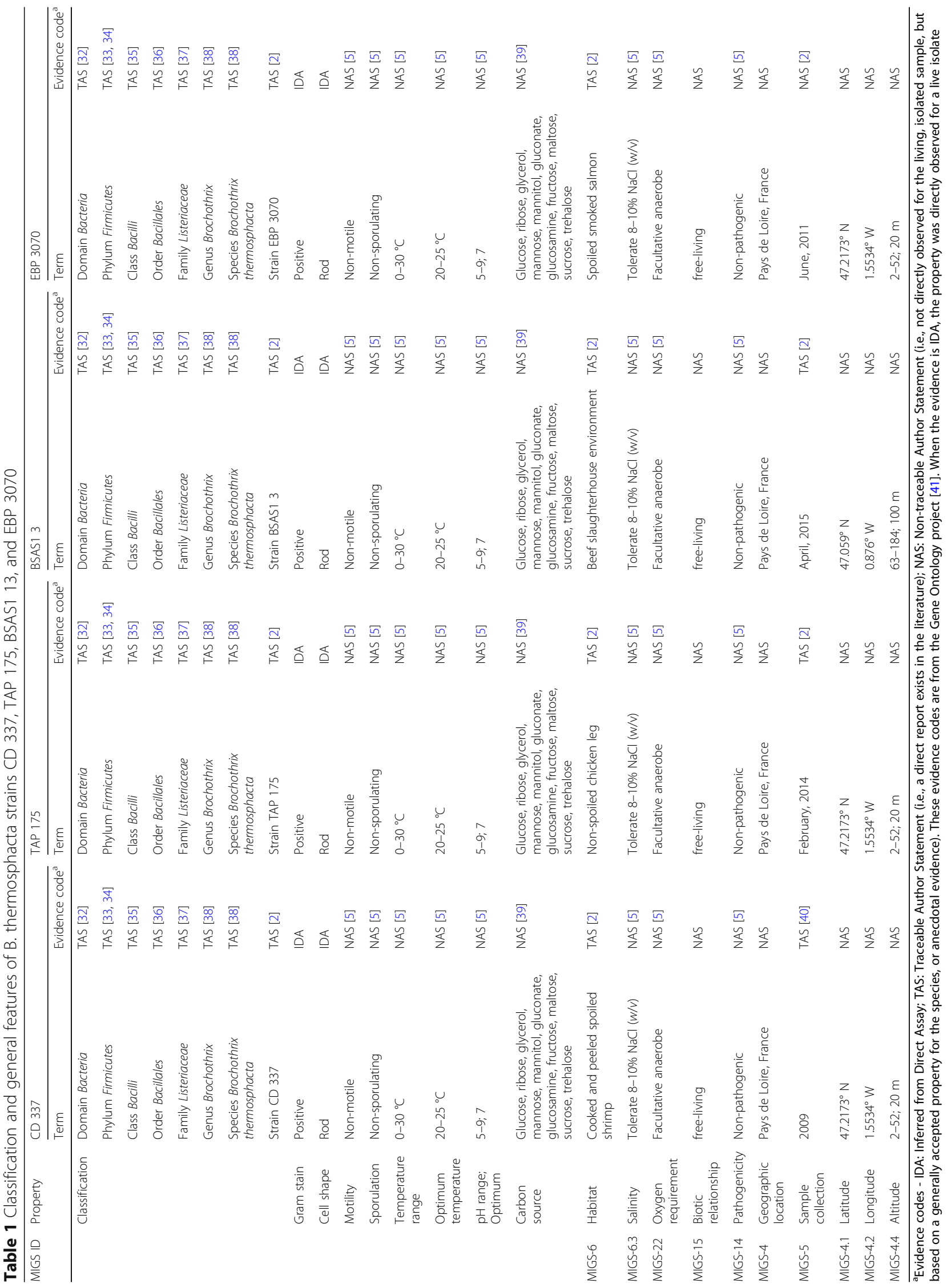




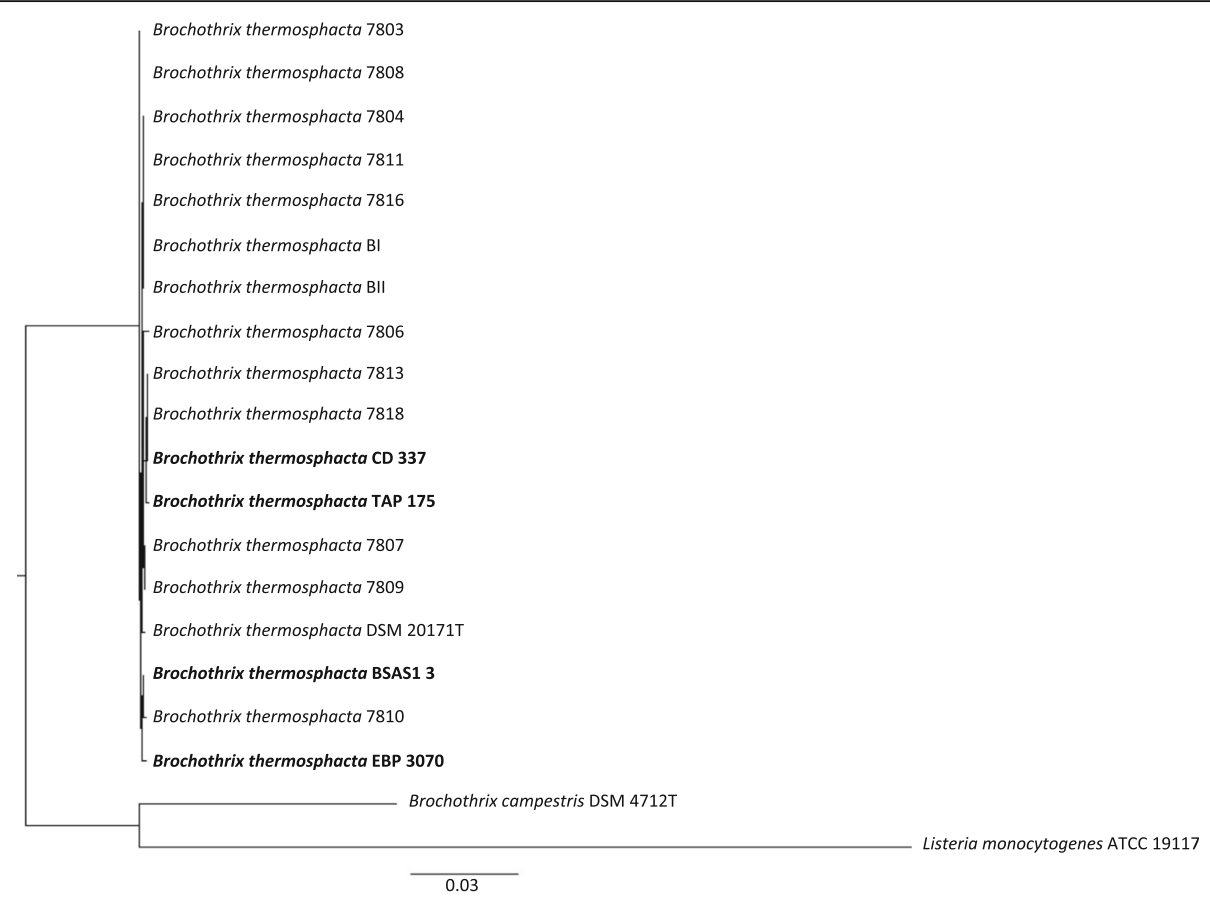

Fig. 1 Phylogenetic tree showing the relationship of the four Brochothrix thermosphacta strains (shown in bold print) to other B. thermosphacta strains the genome of which is publically available. Brochothrix campestris, and Listeria monocytogenes type strains were used as outgroup. Tree is based on MAFFT (v7.309) [42] aligned complete rpoB gene sequences. The tree was built using FastTree (v2.1.5) then visualized with FigTree (v1.4.3)

flow and anion exchange chromatography, eluted in $5 \mathrm{ml}$ QF buffer (Qiagen) and precipitated with $3.5 \mathrm{ml}$ isopropanol. DNA was collected by centrifugation for $15 \mathrm{~min}$ at $4{ }^{\circ} \mathrm{C}$ and $10,000 \times \mathrm{g}$ and then air dried for $10 \mathrm{~min}$. DNA was resuspended in $100 \mu \mathrm{l}$ TE buffer (10 Mm Tris-HCl, $1 \mathrm{mM}$ EDTA, pH 8.0) for two hours at $55{ }^{\circ} \mathrm{C}$. DNA integrity was checked on a $0.8 \%$ agarose gel. DNA concentration and purity were checked using Nanodrop spectrophotometer 2000 (Thermo Scientific). The ratio $260 \mathrm{~nm}$ and $280 \mathrm{~nm}$ was assessed to be 1.9.

\section{Genome sequencing and assembly}

B. thermosphacta CD 337 sequence reads were generated at GeT-PlaGe (Plateforme Génomique), INRA Auzeville, France with a single-molecule-real-time (SMRT) using Pacific Biosciences RS II sequencing technology (Table 2). A total of 113,824 reads was produced. De-novo assembly was carried out using CANU version 1.3 with standard parameters [9]. Raw data were aligned then polished with pbalign and quiver de smrtshell-2.3.0, respectively. The resulting contig was circularized with circlator (version 1.3.0) [10]. For the three other strains TAP 175, BSAS1 3, and EBP 3070, library preparation and genome sequencing were carried out at GeT-Biopuces platform (INSA, Toulouse, France) using S5 sequencer from Ion Torrent technology (Table 2). The resulted reads, approximately $2.60,2.26$, and 2.88 million for TAP 175, BSAS1 3 and EBP 3070, respectively, were de-novo assembled using SPAdes (version 3.9.0) with default parameters [11]. The assembly resulted in 57,83 , and 71 contigs, respectively.

\section{Genome annotation}

The new complete and draft genome sequences were integrated in the MicroScope platform hosted in the Genoscope for automatic annotation [12]. This tool uses multiple databases: TrEMBL, SwissProt, FigFam, PubMed, InterPro, etc. The Microscope platform also provides links to databases as PkGDB, MicroCyc, KEGG for extracting genomic and metabolic data from the pathway genome database [12]. Expert annotation was performed for all the genes of B. thermosphacta CD 337 genome using the gene annotation editor. Expert manual annotations were then transferred from CD 337 on close orthologs (i.e. $>90 \%$ identity on $>80 \%$ length or $>85 \%$ identity when syntheny was observed) of the draft genomes from the three other $B$. thermospacta strains.

\section{Genome properties}

The circular genome of B. thermosphacta CD 337 is $2,594,337$ nucleotides with a $36.46 \%$ GC content (Table 3) and contains one finalized chromosome (Fig. 3). This genome contains 2943 protein coding sequences (CDS). The draft genomes of strains TAP 175, BSAS1 3, and EBP 3070 consist in 57, 83, and 71 contigs, respectively. The genome of $B$. thermosphacta TAP 175 has an 

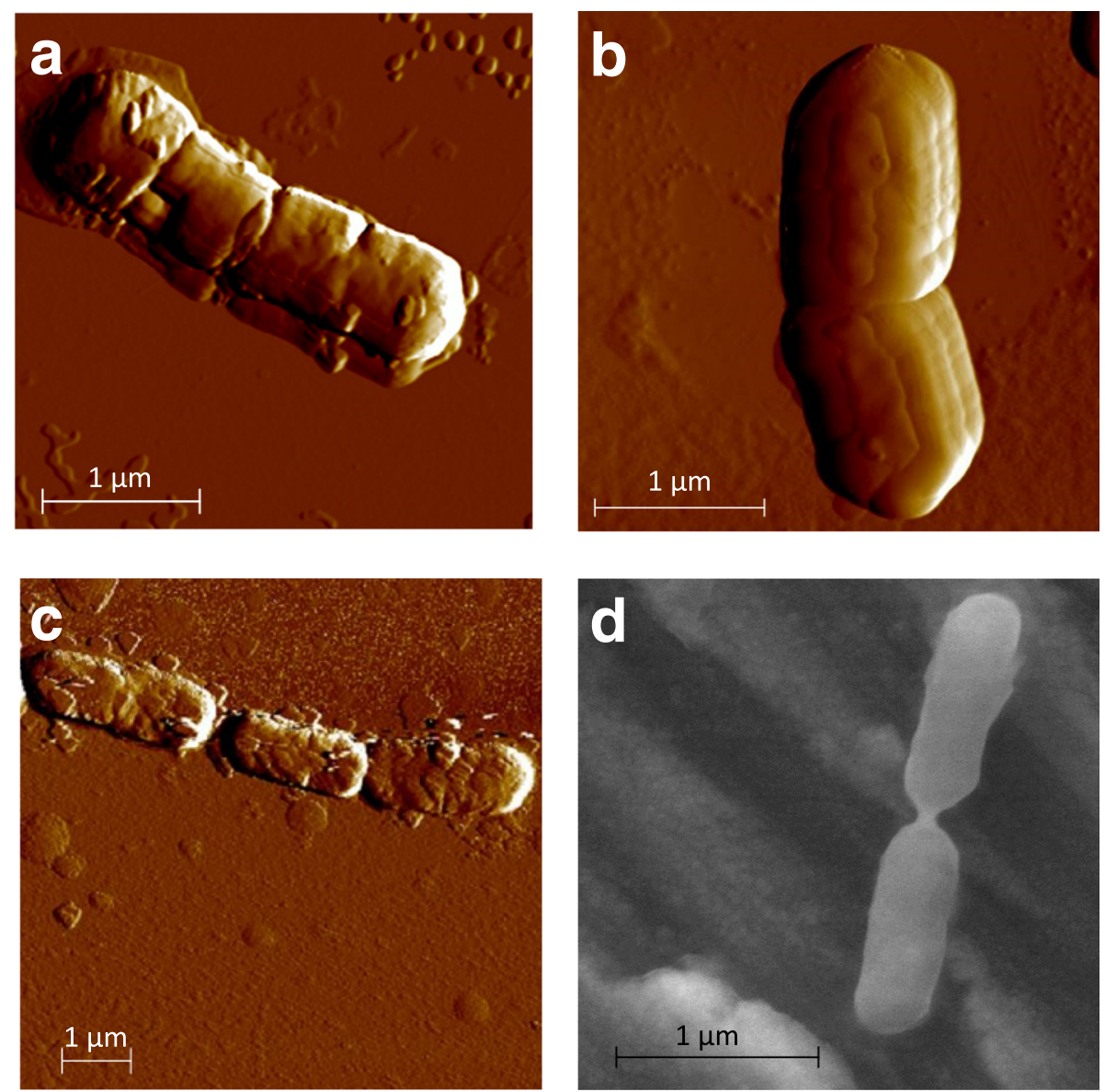

Fig. 2 Microscopy pictures of liquid-grown Brochothrix thermosphacta cultures. Brochothrix thermosphacta CD 337 (a), B. thermosphacta EBP 3070 (b), B. thermosphacta BSAS1 3 (c) were imaged by atomic force microscopy, and B. thermosphacta TAP 175 (d) was generated by scanning electron microscopy. The scale bars represent $1 \mu \mathrm{m}$

estimated size of $2,506,748$ bp, with a $36.28 \%$ GC content. That of B. thermosphacta BSAS1 3 encompasses $2,617,996$ bp $(36.20 \% \mathrm{G}+\mathrm{C})$, and that of the strain EBP 3070 is $2,541,668$ bp long ( $36.22 \% \mathrm{G}+\mathrm{C})$ (Fig. 3). The three genomes contain 2515, 2668, and 2611 CDS, respectively. The genome properties and statistics are summarized in Table 3, and the number of genes assigned to COG functional categories in Table 4.

A high degree of genomic sequence similarity among the four $B$. thermosphacta strains was observed by the calculation of Average Nucleotide Identity (ANI) using OrthoANIu, an orthologous ANI algorithm [13]. Strain to strain genomic comparisons showed orthoANI (Orthologous Average Nucleotide Identity) values varying from 98.94 to $99.11 \%$, correlating thus with previous observations on other $B$. thermosphacta genome sequences $[3,4]$.

\section{Insights from the genome sequence}

Comparative genomics of the pan genome was based on MicroScope gene/protein families (MICFAMs). This tool classifies proteins in homolog groups of proteins sharing at least $80 \%$ amino-acid identity and $80 \%$ alignment coverage [14]. The core genome includes MICFAMs associated with at least one gene from every compared genomes. The variable-genome includes MICFAM present in at least two compared genomes. Specific genome includes genes that are singletons and present in only one genome.

The pan genome of strains CD337, TAP 175, BSAS1 3, and EBP 3070 comprised 10,373 genes. Among them, 8339 genes, corresponding to 2073 MICFAMs were shared by all strains and therefore represent the core genome. The variable genome contained 2034 genes grouped into 1371 MICFAMs. This analysis revealed that the four strains contain $10.19 \%, 5.46 \%, 10.66 \%$ and 9.59\% strain-specific coding sequences, respectively. (Fig. 4a). The same analysis was performed on the 3 complete genomes, i.e. the newly sequenced genome CD337 and the two publicly available genomes of $B$. thermosphacta BI and BII, two strains isolated from ground chicken meat (Fig. 4b) [4]. From these 3 
Table 2 Project information

\begin{tabular}{|c|c|c|c|c|c|}
\hline MIGS ID & Property & Term, CD 337 & Term, TAP 175 & Term, BSAS1 3 & Term, EBP 3070 \\
\hline MIGS 31 & Finishing quality & Complete circular genome & Draft genome & Draft genome & Draft genome \\
\hline MIGS-28 & Libraries used & $\begin{array}{l}\text { 20-kb Template Preparation } \\
\text { Using BluePippin } \\
\text { Size-Selection System } \\
\text { (15-kb size cutoff) }\end{array}$ & $\begin{array}{l}\text { NEB Next Fast DNA } \\
\text { fragmentation and library } \\
\text { prep (NEB Biolabs) }\end{array}$ & $\begin{array}{l}\text { NEB Next Fast DNA } \\
\text { fragmentation and library } \\
\text { prep (NEB Biolabs) }\end{array}$ & $\begin{array}{l}\text { NEB Next Fast DNA } \\
\text { fragmentation and } \\
\text { library prep } \\
\text { (NEB Biolabs) }\end{array}$ \\
\hline MIGS 29 & $\begin{array}{l}\text { Sequencing } \\
\text { platforms }\end{array}$ & $\begin{array}{l}\text { PacBio RSII } \\
\text { (Pacific BioSciences) }\end{array}$ & Ion S5 (Ion Torrent) & Ion S5 (Ion Torrent) & Ion S5 (Ion Torrent) \\
\hline MIGS 31.2 & Fold coverage & 526.48 & 270.67 & 206.01 & 243.65 \\
\hline MIGS 30 & Assemblers & CANU version 1.3 & SPAdes (version 3.9.0) & SPAdes (version 3.9.0) & SPAdes (version 3.9.0) \\
\hline \multirow[t]{6}{*}{ MIGS 32} & $\begin{array}{l}\text { Gene calling } \\
\text { method }\end{array}$ & $\begin{array}{l}\text { MicroScope Genoscope } \\
\text { Plateform [12] }\end{array}$ & $\begin{array}{l}\text { MicroScope Genoscope } \\
\text { Plateform [12] }\end{array}$ & $\begin{array}{l}\text { MicroScope Genoscope } \\
\text { Plateform [12] }\end{array}$ & $\begin{array}{l}\text { MicroScope } \\
\text { Genoscope } \\
\text { Plateform [12] }\end{array}$ \\
\hline & Locus Tag & BTCD & BTTAP & BTBSAS & BTEBP \\
\hline & Genbank ID & ERZ500814 & ERZ500815 & ERZ500816 & ERZ500817 \\
\hline & $\begin{array}{l}\text { GenBank Date } \\
\text { of Release }\end{array}$ & 25 May 2018 & 25 May 2018 & 25 May 2018 & 25 May 2018 \\
\hline & GOLD ID & & & & \\
\hline & BIOPROJECT & PRJEB25018 & PRJEB25018 & PRJEB25018 & PRJEB25018 \\
\hline \multirow[t]{2}{*}{ MIGS 13} & $\begin{array}{l}\text { Source Material } \\
\text { Identifier }\end{array}$ & & & & \\
\hline & Project relevance & Food spoiler & Food spoiler & Food spoiler & Food spoiler \\
\hline
\end{tabular}

complete genomes, the pan genome comprised 7746 genes (2922 MICFAMs), with 6667 genes (2189 MICFAMs) constituting the core genome, and 1079 genes (733MICFAMs) the variable genome. Strain specific genome of B. thermosphacta BI, BII, and CD 337 comprised $3.21 \%, 0.94 \%, 12.06 \%$, and genes, respectively. Strainspecific genes included some proteins involved in regulatory functions, cell surface composition, use of various carbon sources, or bacteriocin production. In particular we observed a four gene cluster, unique to B. thermosphacta CD 337 putatively encoding at least part of the machinery for the production of a type 2 lantibiotic. It encompasses a gene for putative lantibiotic modifying enzyme, lanthionine synthetase C-like, and

Table 3 Genome statistics

\begin{tabular}{|c|c|c|c|c|c|c|c|c|}
\hline \multirow[t]{2}{*}{ Attribute } & \multicolumn{2}{|l|}{ CD 337} & \multicolumn{2}{|l|}{ TAP 175} & \multicolumn{2}{|l|}{ BSAS1 3} & \multicolumn{2}{|l|}{ EBP 3070} \\
\hline & Value & $\%$ of Total & Value & $\%$ of Total & Value & $\%$ of Total & Value & $\%$ of Total \\
\hline Genome size (bp) & $2,594,337$ & 100 & $2,506,748$ & 100 & $2,617,996$ & 100 & $2,541,668$ & 100 \\
\hline DNA coding (bp) & $2,182,130$ & 84.11 & $2,136,251$ & 85.22 & $2,213,516$ & 84.55 & $2,118,751$ & 83.36 \\
\hline DNA G + C (bp) & 945,895 & 36.46 & 909,448 & 36.28 & 947,714 & 36.20 & 920,592 & 36.22 \\
\hline DNA scaffolds & 1 & 100 & 57 & 100 & 83 & 100 & 71 & 100 \\
\hline Total genes & 2743 & 100 & 2638 & 100 & 2796 & 100 & 2740 & 100 \\
\hline Protein coding genes & 2593 & 94.53 & 2515 & 95.3 & 2668 & 95.4 & 2611 & 95.3 \\
\hline RNA genes & 28 & 1.0 & 6 & 0.2 & 8 & 0.3 & 9 & 0.3 \\
\hline Pseudo genes & 38 & 1.4 & 43 & 1.6 & 57 & 2.0 & 102 & 3.7 \\
\hline Genes in internal clusters & N/D & - & N/D & - & N/D & - & N/D & - \\
\hline Genes with function prediction & 2031 & 74.04 & 1928 & 73.1 & 1957 & 70.0 & 1954 & 71.3 \\
\hline Genes assigned to COGs & 2486 & 90.6 & 2429 & 92.1 & 2472 & 88.4 & 2432 & 88.7 \\
\hline Genes with Pfam domains & 2026 & 73.9 & 1982 & 75.1 & 2040 & 73.0 & 2002 & 73.1 \\
\hline Genes with signal peptides & 85 & 3.1 & 83 & 3.1 & 83 & 3.0 & 85 & 3.1 \\
\hline Genes with transmembrane helices & 392 & 14.3 & 384 & 14.5 & 386 & 13.8 & 389 & 14.2 \\
\hline CRISPR repeats & 1 & 0.04 & 2 & 0.07 & 1 & 0.03 & 0 & 0 \\
\hline
\end{tabular}



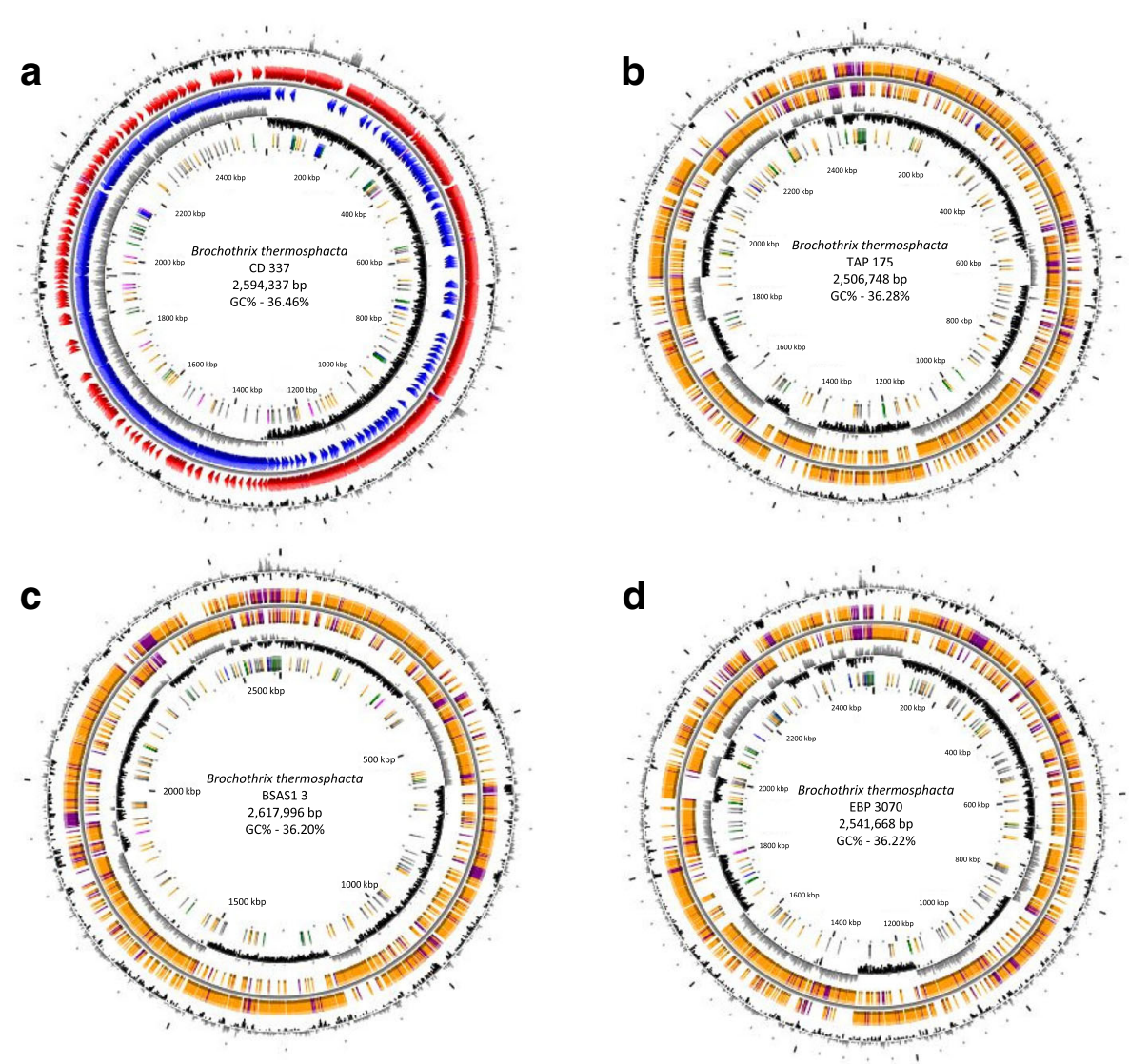

Fig. 3 Circular views of genome sequences of Brochothrix thermosphacta CD 337 (a), B. thermosphacta TAP 175 (b), B. thermosphacta BSAS1 3 (c), and B. thermosphacta EBP 3070 (d). The circular display shows, from outside to inside: (i) GC percentage; (ii) Predicted CDSs transcribed in the clockwise direction; (iii) Predicted CDSs transcribed in the counterclockwise direction. In (ii) and (iii), red and blue colors represent MaGe validated annotations, orange color represents the MicroScope automatic annotation with a reference genome, and the purple color represents Primary/ Automatic annotations; (iv) GC skew (G+C/G-C) and (v) color-code representing rRNA (blue), tRNA (green), miscellaneous RNA (orange),

Transposable elements (pink) and pseudogenes (grey)

lantibiotic leader peptide-processing serine protease, and a small 70 amino acid peptide similar to lichenicidin, a lantibiotic produced by Bacillus licheniformis [15]. However, a large proportion of these strain-specific genes encode proteins of unknown functions or are fragmented genes. The list of the specific genes of B. thermosphacta CD 337, $\mathrm{BI}$, and BII is given in (Additional file 1: Table S1, Table S2, and Table S3, respectively).

Bacteriophage prediction results using PHAST (PHAge Search Tool) [16] showed that the four genomes contained at least one bacteriophage region. Similarities to phages previously described were provided based on the highest number of proteins most similar to those in the region. A schematic representation of the phage content of the four strains is presented in (Additional file 2: Figure S1). Both CD 337 and EBP 3070 harbored a complete phage (about $49 \mathrm{~Kb}$ ) similar to LP-101 of L. monocytogenes [17] and an incomplete NF5 bacteriophage $(18.8 \mathrm{~Kb})$ previously described in $B$. thermosphacta [18]. CD 337 comprised a third region $(18.8 \mathrm{~Kb})$ similar to
L. monocytogenes B054 phage [19]. TAP 175 genome comprised only one bacteriophage region consisting in a fraction of the $B$. thermosphacta NF5 bacteriophage. Strain BSAS1 3 harbored two complete bacteriophages similar to IME_SA4 and SANTOOR1 described in Staphylococcus haemolyticus and Enterococcus faecalis, respectively.

Since clustered regularly interspaced short palindromic repeats (CRISPR) and CRISPR-associated (Cas) proteins constitute an adaptive immune system against bacteriophages and other foreign genetic elements in bacteria and archaea [20], we investigate the occurrence of CRISPR-Cas systems in the four genomes of the present study. Interestingly, we found a diversity between strains regarding CRISPR/Cas System (Additional file 1: Table S4). Indeed, in the genome of the strain EBP 3070 we do not found CRISPR/Cas System, in the genome of the strain CD 337 we found only one putative CRISPR-associated endoribonuclease, while in the genome of the strain BSAS1 3 we found a CRISPR-Cas 
Table 4 Number of genes associated with general COG functional categories

\begin{tabular}{|c|c|c|c|c|c|c|c|c|c|}
\hline \multirow[t]{2}{*}{ Code } & \multicolumn{2}{|c|}{ CD 337} & \multicolumn{2}{|c|}{ TAP 175} & \multicolumn{2}{|c|}{ BSAS1 3} & \multicolumn{2}{|c|}{ EBP 3070} & \multirow[t]{2}{*}{ Description } \\
\hline & Value & \%age & Value & \%age & Value & \%age & Value & \%age & \\
\hline J & 158 & 6.09 & 161 & 6.40 & 159 & 5.96 & 164 & 6.28 & Translation, ribosomal structure and biogenesis \\
\hline A & ND & - & ND & - & ND & - & ND & - & RNA processing and modification \\
\hline K & 237 & 9.14 & 235 & 9.34 & 242 & 9.07 & 234 & 8.96 & Transcription \\
\hline L & 131 & 5.05 & 125 & 4.97 & 139 & 5.21 & 130 & 4.98 & Replication, recombination and repair \\
\hline B & ND & - & ND & - & ND & - & ND & - & Chromatin structure and dynamics \\
\hline D & 35 & 1.35 & 35 & 1.39 & 36 & 1.35 & 34 & 1.30 & Cell cycle control, Cell division, chromosome partitioning \\
\hline V & 63 & 2.43 & 55 & 2.19 & 52 & 1.95 & 57 & 2.18 & Defense mechanisms \\
\hline $\mathrm{T}$ & 100 & 3.86 & 95 & 3.74 & 98 & 3.67 & 99 & 3.79 & Signal transduction mechanisms \\
\hline M & 117 & 4.51 & 106 & 4.21 & 119 & 4.46 & 109 & 4.17 & Cell wall/membrane biogenesis \\
\hline N & 16 & 0.62 & 12 & 0.48 & 17 & 0.64 & 15 & 0.57 & Cell motility \\
\hline U & 33 & 1.27 & 27 & 1.07 & 29 & 1.09 & 28 & 1.07 & Intracellular trafficking and secretion \\
\hline O & 71 & 2.74 & 69 & 2.74 & 66 & 2.47 & 69 & 2.64 & Posttranslational modification, protein turnover, chaperones \\
\hline C & 106 & 4.09 & 106 & 4.21 & 107 & 4.01 & 105 & 4.02 & Energy production and conversion \\
\hline G & 233 & 8.98 & 232 & 9.22 & 227 & 5.81 & 221 & 8.46 & Carbohydrate transport and metabolism \\
\hline E & 244 & 9.41 & 247 & 9.82 & 246 & 9.22 & 242 & 9.27 & Amino acid transport and metabolism \\
\hline $\mathrm{F}$ & 72 & 2.78 & 71 & 2.82 & 71 & 2.66 & 71 & 2.72 & Nucleotide transport and metabolism \\
\hline $\mathrm{H}$ & 76 & 2.93 & 76 & 3.02 & 75 & 2.81 & 80 & 3.06 & Coenzyme transport and metabolism \\
\hline । & 60 & 2.31 & 62 & 2.46 & 60 & 2.25 & 58 & 2.22 & Lipid transport and metabolism \\
\hline$P$ & 159 & 6.13 & 159 & 6.32 & 158 & 5.92 & 156 & 5.97 & Inorganic ion transport and metabolism \\
\hline Q & 40 & 1.54 & 39 & 1.55 & 38 & 1.42 & 37 & 1.42 & Secondary metabolites biosynthesis, transport and catabolism \\
\hline $\mathrm{R}$ & 320 & 12.34 & 310 & 12.33 & 318 & 11.92 & 307 & 11.76 & General function prediction only \\
\hline S & 211 & 8.14 & 206 & 8.19 & 215 & 8.06 & 215 & 8.23 & Function unknown \\
\hline- & 107 & 4.14 & 86 & 3.49 & 196 & 10.05 & 179 & 6.89 & Not in COGs \\
\hline
\end{tabular}

The total is based on the total number of protein coding genes in the genome

system composed by three CRISPR-associated endoribonucleases (Cas1, Cas2, and Cas9) and a Type II-A CRISPR-associated protein Csn2. Finally, in the genome of the strain TAP 175 we found a CRISPR-Cas system composed by at least 5 CRISPR-associated endoribonucleases
(Cas1, Cas2, Cas4, Cas5d and Cas9) and a Type II-A CRISPR-associated protein Csn2. This diversity in four strains could participate to explain their adaptation and survival to various ecological niches, as CRISPR/Cas System provides bacterial immunity a

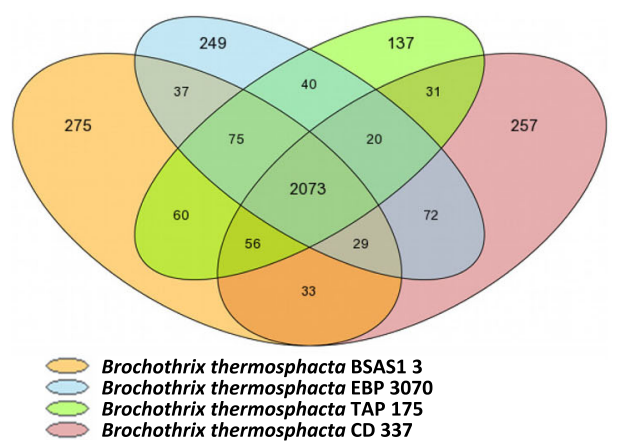

b

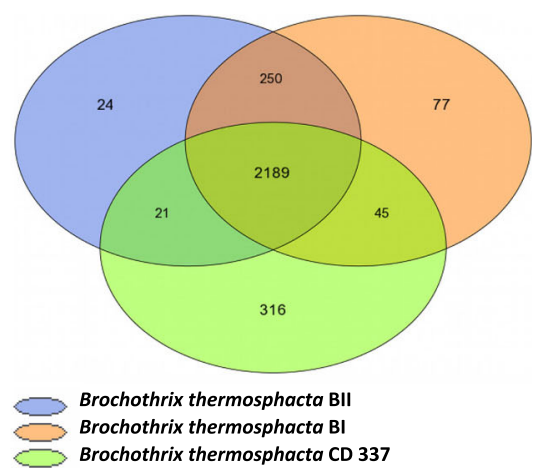

Fig. 4 Core and pan genomes. Venn diagram analysis of (a) Brochothrix thermosphacta CD 337, B. thermosphacta TAP 175, B. thermosphacta BASA1 3, and B. thermosphacta EBP 3070; and (b) B. thermosphacta CD 337, B. thermosphacta BI, and B. thermosphacta BII. Values on diagram represent the numbers of MICFAM families for each organism intersections 
against lytic bacteriophages, which occur in food and food environments [21, 22].

B. thermosphacta CD 337 complete genome contained no plasmid. However, putative plasmids were found in the three draft genomes as shown in (Additional file 2: Figure S2). Indeed, these contained contigs harboring genes related to plasmid proteins (ie: repB involved in plasmid replication or $\mathrm{mob} / \mathrm{pre}$ genes involved in recombination and conjugative mobilization). Such a 4557 bp long contig was found in both TAP 175 and BSAS1 3 with a high similarity degree between the two strains. This plasmid encoded also a protein annotated as a quaternary ammonium compound-resistance protein. The genome of EBP 3070 harbored two putative plasmids (8624 bp; $5011 \mathrm{bp).} \mathrm{One} \mathrm{of} \mathrm{these} \mathrm{may} \mathrm{confer}$ tetracycline resistance as it carried a gene encoding a multifunctional tetracycline antiporter which was $81 \%$ identical to the $\operatorname{tet} B(L)$ gene of Bacillus subtilis [23].

\section{Extended insights}

Functions putatively involved in the niche adaptation and in the spoilage properties were searched in the genomes of the four strains. We found a large repertoire of substrate specific genes from the phosphoenolpyruvate dependent phosphotransferase system (PTS). The genomes of the four strains contained genes for glucose, maltose, fructose, mannose, trehalose, cellobiose, mannitol, beta-glucosides, and $\mathrm{N}$-acetylglucosamine transport and phosphorylation. Genes encoding transporters for ribose, glycerol-3-phosphate, maltose, and myo-inositol were also present, attesting the large capacity of carbon sources used by $B$. thermosphacta.

No major difference for sugar utilization was noticed between the four strains. In addition predicted metabolic pathways of our strains were very similar to those previously described in other B. thermosphacta strains [3]. Briefly, all genes required for glycolysis and the pentose phosphate pathway were present in all strains. The citrate cycle was incomplete since only four of the eight enzymes were detected. The genes coding for alpha-ketoglutarate dehydrogenase (EC 1.2.4.2), succinate thiokinase (EC 6.2.1.4), succinate dehydrogenase (EC 1.3.5.1), and malate dehydrogenase (EC 1.1.1.37) were absent. Moreover, the gene coding the pyruvate carboxylase (EC 6.4.1.1) was present while that of the fumarate reductase (EC 1.3.5.4) was absent.

Genes involved in the production of molecules associated to meat or seafood spoilage, as lactate, ethanol, acetate, acetoin, diacetyl, and 2.3-butanediol were identified. Although we had previously observed differences between strains in their ability to produce acetoin, the butA gene encoding diacetyl reductase [(S)-acetoin forming], as well as its 300 bp upstream region was $100 \%$ identical in all strains. Conversely, the $b d h A$ gene encoding (R,R)-2,3 butanediol dehydrogenase able to convert $(\mathrm{R}, \mathrm{R})$ - 2,3-butanediol or diacetyl to acetoin presented $100 \%$ identity between BSAS1 3 and CD 337 but, amino-acid at position 201 (alanine) was replaced by glutamic acid in both EBP 3070 and TAP 175 enzymes, thus introducing a negative charge. Interestingly replacing aspartic acid by alanine in glycerol dehydrogenase of Escherichia coli improved its activity toward 1,3-butanediol [24]. As EBP 3070 and TAP 175 had a similar pattern for acetoin and diacetyl production (they were among the highest producers of acetoin and diacetyl in shrimp juice, and among the lowest in beef) we can hypothesize that the alanine/glutamate replacement may be involved in the different acetoin production levels we previously observed (Fig. S3).

Moreover, the upstream region of the $b d h A$ gene of EBP 3070 and TAP 175 were identical and showed differences with that of BSAS1 3 at positions $-141,-137$, $-110,-67$, and -43 upstream from the start codon suggesting transcriptional regulation of $b d h A$ might be different. However, CD 337 presented the same differences as EBP 3070 and TAP 175 plus an additional one at position -46 .

In addition, genes involved in the production of isovaleric, isobutyric, and 2-methylbutyric branched-chain fatty acids were found in the genome of the four strains. These compounds, associated with off-odors, were suggested to be produced from the degradation of branched-chain amino acids leucine, valine, and isoleucine, respectively [25]. The catabolism of leucine can also lead further to the synthesis of 3-methylbutanal and 3-methylbutanol. 3-methybutanal, a branched-chain aldehyde has been described as associated to the production of desirable aroma in many cheeses [26], while it is responsible for off-odors in meat and seafood products $[27,28]$. The pathway of 3 -methylbutanal production from leucine catabolism has been described in lactic acid bacteria. The first step of this pathway is the transamination of leucine to $\alpha$-ketoisocaproate which is the central metabolite in leucine degradation [29]. Then the formation of 3-methylbutanal may occur in two possible metabolic pathways: directly via the non-oxidative decarboxylation by an $\alpha$-ketoacid decarboxylase or indirectly through an oxidative decarboxylation by $\alpha$-ketoacid dehydrogenase [26]. Investigation of $B$. thermosphacta genomes showed that all the genes encoding enzymes required for isovalerate, 3-methylbutanal and 3-methylbutanol production from leucine were present (Fig. 5). Interestingly, the $\alpha$-ketoacid decarboxylase from BSAS1 3, TAP 175, and EBP 3070 was $100 \%$ identical (except glutamine 311 replaced by a histidine in EPB 3070) but was mutated in CD 337 resulting in a fragmented gene and 2 mutations on amino acids 200 and 205. We also noticed that the gene encoding the E1 component, $\beta$ subunit of the $\alpha$-keto acid dehydrogenase 


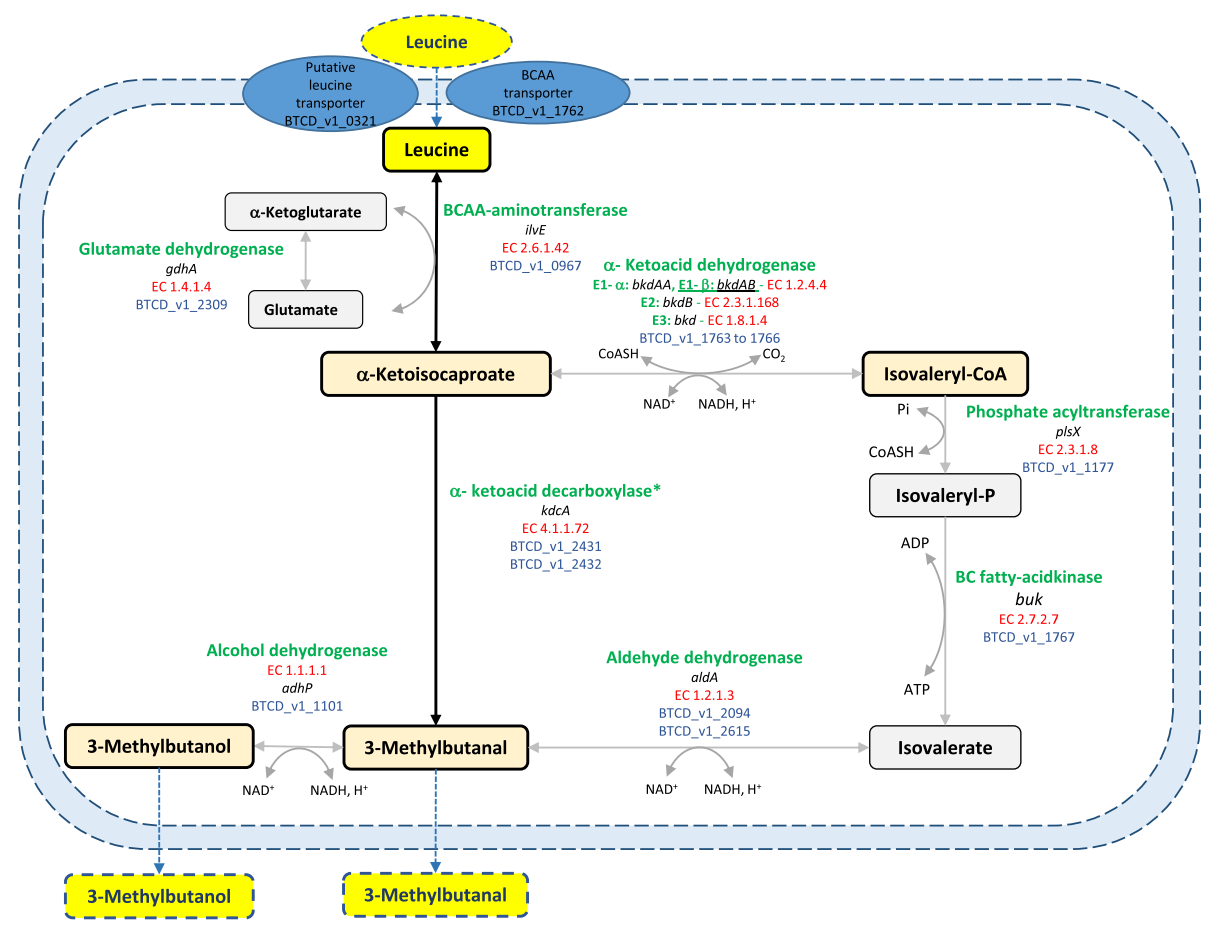

Fig. 5 Probable metabolic pathway for the biosynthesis of 3-methylbutanal from L-leucine degradation by B. thermosphacta. All the genes encoding the necessary enzymes for the direct (dark line) and the indirect (gray line) pathways were present. Alcohol dehydrogenase was also present. BCAA refrers to branched-chain amino acids. * The $k d c A$ gene is fragmented in $B$. thermosphacta CD 337 . The underlined gene bkdAB is fragmented in BSAS1 3

was $100 \%$ identical in CD 337, EPB 3070, and TAP 175 but fragmented in BSAS1 3. This suggests that production of isovalerate, 3-methylbutanol, and 3-methylbutanal may differ between strains and use different pathways, possibly impacting the spoilage potential of the strains.

Since B. thermosphacta has been associated to the production of biogenic amines [30] the presence of amino acid decarboxylases was searched in the genomes. Genes encoding histidine decarboxylase and tyrosine decarboxylase responsible for the production of histamine and tyramine, respectively, were not found. Nevertheless, all the genomes harbored the genes encoding the $\mathrm{ABC}$ transporter complex PotABCD involved in the import of spermidine and putrescine, two polyamines present in meat and fish.

A putative cell-wall associated adhesin was found in CD 337 genome, which was absent or truncated in other strains. Adhesins may promote substrate adhesion and survival in the environment, and the presence of adhesin in only some strains may contribute to their different niche adaptation. Nine proteins annotated as containing an LPxTG-like motif were detected in CD 337. In addition, among the genes encoding exported proteins of unknown functions two CDS (BTCD_v1_656 and BTCD_v1_1960) also harbored an LPxTG motif and a signal peptide, as well as a protein annotated as a putative fimbrial isopeptide formation D2 domain-containing protein (BTCD_v1_1958). Such proteins are surface proteins covalently linked to the bacterial cell wall by a sortase. All were well conserved in the four strains, except three (BTCD_v1_1958 to 1960) which were unique to CD 337 and located in a genomic island of $24,132 \mathrm{bp}$. This island also encompassed genes encoding putative recombinases and transposases suggesting its acquisition through horizontal gene transfer. Putative sortase genes were also present, showing this island may indeed encode functions for specifically linking the three LPxTG proteins to the cell surface. It also hosted genes encoding proteins involved in polysaccharide metabolism as a putative polysaccharide deacetylase, a putative polysialyltransferase, and proteins resembling the NeuBCDA enzymes involved in the amino sugar $\mathrm{N}$-acetyl neuraminic acid (sialic acid) metabolism. Futhermore, a putative O-acetyltransferase EpsM (BTCD_v1_0680) most probably involved in biofilm formation was also found in CD 337 genome, conserved in B. thermosphacta BI and BII genomes, but absent in the three other strain genomes of the present study (EPB 3070, TAP 175 and BSAS1 3). It has been shown in $B$. subtilis a similar O-acetyltransferase (EpsM), which is a member of the eps operon, involved in the production of the exopolysaccharide (EPS) component of the extracellular matrix during biofilm formation [31]. 
All these proteins may have an important role in the survival and the persistence of bacteria in the food-processing environment. Such differences in the gene repertoire between the four strains might correlate to the different substrates our strains were isolated from.

\section{Conclusions}

The four strains we selected for comparative genomics were chosen as diverse as possible (different ecological origin, different ability to produce some spoilage molecules, and belonging to different PFGE and Rep-PCR clusters). However, a high genome content similarity was observed as previously reported by other authors on different meat product issued strains. The major differences we observed in the gene content were represented by phages or plasmids, restriction/modification systems, cell surface functions, or use of various carbon sources. These could participate to their fitness or adaptation to various niches, in particular the functions involved in carbon sources utilization or those associated to cell surface or adhesion that may help to colonize specific environment. Most of the strain specific genome encompasses proteins of unknown function.

The simple comparison of the variable genome could not explain the differences we observed in the ability to produce acetoin and diacetyl. Nevertheless, we showed that mutations (fragmentation or point mutation) in genes encoding enzymes involved in the production of VOCs and differences in the DNA sequences located upstream from start codons, thus potentially in the promoter region of these genes may lead to different efficacies to produce such VOCs and therefore to spoil meat or seafood products.

Therefore, the diversity of spoilage potential of $B$. thermosphacta on various foods reported in the literature may result from i) a strain dependent specificity to adapt to different ecological niches, characterized by strain specific genome content; ii) a strain dependent capacity to produce malodorous molecules driven by the presence/ absence/mutations of enzymes involved in the catabolism of branched chain amino acids and pyruvate; and iii) a strain dependent capacity to express the corresponding genes.

\section{Additional files}

Additional file 1: List of the specific genes of B. thermosphacta CD 337 (Table S1), BI (Table S2), and BII (Table S3). Table S4. List of CRISPR genes found in CD 337, BSAS1 3, and TAP 175. (XLSX 41 kb)

Additional file 2: Figure S1. Schematic representation of phage content of the four $B$. thermosphacta strains. The phage identification was given by
PHAST program [16]. It refers to the phage with the highest number of proteins most similar to those in the region. The phages were represented by boxes surrounded by solid line (intact phages) or dashed line (incomplete phages). The phage size and the number of CDS were also given. Figure S2. Schematic representation of putative plasmids content of three $B$. thermosphacta strains. The plasmids size and the CDS content were given. Figure S3. Metabolic pathway for the production of acetoin and diacetyl from pyruvate degradation. All genes encoding the necessary enzymes were found. (PPTX $47 \mathrm{~kb}$ )

\section{Abbreviations}

CFU: Colony forming unit; KEGG: Kyoto Encyclopedia of Genes and Genomes; MALDI-TOF: Matrix assisted laser desorption ionization - time of flight; MICFAM: MicroScope Family; PFGE: Pulsed-field gel electrophoresis; PkGDB: Prokaryotic Genome DataBase:; Rep-PCR: Repetitive element palindromic based-polymerase chain reaction; STAA: Streptomycin-thallous acetate-actidione; VOCs: Volatile organic compounds

\section{Acknowledgements}

We thank Angélina D'Orlando and INRA BIBS platform (composante Microscopie) for microscopy imaging. We would like to thank the platform GeT-Biopuces at the Genopole in Toulouse for the S5 sequencing experiments and bioinformatics advices. This work was performed in collaboration with the GeT (Genome and Transcriptome) core facility, Toulouse, France (http://get.genotoul.fr), and was supported by France Génomique National infrastructure, funded as part of "Investissement d'avenir" program managed by Agence Nationale pour la Recherche (contract ANR-10-INBS-09) and by the GET-PACBIO program (« Programme operationnel FEDER-FSE MIDI-PYRENEES ET GARONNE 2014-2020 »). The LABGeM (CEA/IG/Genoscope \& CNRS UMR8030) and the France Génomique National infrastructure (funded as part of Investissement d'avenir program managed by Agence Nationale pour la Recherche, contract ANR-10-INBS-09) are acknowledged for support within the MicroScope annotation platform.

\section{Funding}

This work was financed by "Région Pays de la Loire" (grant to MZ). NI was the recipient of a PhD fellowship from the French Ministry of Higher Education and Research.

\section{Authors' contributions}

$\mathrm{NI}$ participated to conceive the study, performed laboratory experiments (bacterial cultures, DNA extraction), assembled the draft B. thermosphacta genomes, participated to the $B$. thermosphacta CD 337 genome annotation, performed comparative genomic analysis, interpreted the results, and wrote the manuscript. $O B$ and $A R$ sequenced the complete genome of $C D$ 337. CK assembled the complete genome of CD 337 and participated to write the manuscript. NM sequenced the draft genomes. MZ conceived the study, participated to the $B$. thermosphacta CD 337 genome annotation and to the comparative genomic analysis, and wrote the manuscript. EJ participated to conceive the study, participated to the genome annotation and wrote the manuscript. All authors read and approved the final manuscript.

\section{Competing interests}

The authors declare that they have no competing interest.

\section{Publisher's Note}

Springer Nature remains neutral with regard to jurisdictional claims in published maps and institutional affiliations.

\section{Author details}

'UMR 1014 SECALIM, INRA, Oniris, Nantes, France. ${ }^{2}$ Plateforme Bio-informatique, Toulouse Genopole, Institut National de la Recherche Agronomique, Castanet-Tolosan, France. ${ }^{3}$ INRA, US 1426, GeT-PlaGe, Genotoul, Castanet-Tolosan, France. ${ }^{4}$ LISBP, Université de Toulouse, CNRS, INRA, INSA, Toulouse, France. 


\section{Received: 15 June 2018 Accepted: 28 September 2018}

Published online: 10 October 2018

\section{References}

1. Illikoud N, Jaffrès $E$, Zagorec M. Brochothrix thermosphacta. Reference Module in Life Sciences; 2018. p. 1-17.

2. Illikoud N, Rossero A, Chauvet R, Courcoux P, Pilet M-F, Charrier T, Jaffrès E, Zagorec M. Genotypic and phenotypic characterization of the food spoilage bacterium Brochothrix thermosphacta. Food Microbiol. 2018; in press.

3. Stanborough T, Fegan N, Powell SM, Tamplin M, Chandry PS. Insight into the genome of Brochothrix thermosphacta, a problematic meat spoilage bacterium. Appl Environ Microbiol. 2017;83(5):e02786-16.

4. Paoli GC, Wijey C, Nguyen L-H, Chen C-Y, Yan X, Irwin PL. Complete genome sequences of two strains of the meat spoilage bacterium Brochothrix thermosphacta isolated from ground chicken. Genome Announcements. 2017;5(47):e01357-17.

5. Stackebrandt $E_{1}$ Jones $D$. The genus Brochothrix. In: The prokaryotes. Dworkin M, Falkow S, Rosenberg E, Schleifer K-H, Stackebrandt E, editors. vol. 4, 3rd edn. Springer US. New York; 2006. 477-491.

6. Gardner GA. A selective medium for the enumeration of Microbacterium thermosphactum in meat and meat products. J Appl Bacteriol. 1966;29(3):455-60.

7. Gardner GA. Streptomycin-thallous acetate-actidione (STAA) agar: a medium for the selective enumeration of Brochothrix thermosphacta. Int J Food Microbiol. 1985;2(1-2):69-70.

8. Falentin H, Deutsch S-M, Loux V, Hammani A, Buratti J, Parayre S, Chuat V, Barbe $V$, Aury J-M, Jan G, et al. Permanent draft genome sequence of the probiotic strain Propionibacterium freudenreichii CIRM-BIA 129 (ITG P20). Stand Genomic Sci. 2016;11(1):6.

9. Koren S, Walenz BP, Berlin K, Miller JR, Bergman NH, Phillippy AM. Canu: scalable and accurate long-read assembly via adaptive k-mer weighting and repeat separation. Genome Res. 2017;27(5):722-36.

10. Hunt M, Silva ND, Otto TD, Parkhill J, Keane JA, Harris SR. Circlator: automated circularization of genome assemblies using long sequencing reads. Genome Biol. 2015;16(1):294.

11. Bankevich A, Nurk S, Antipov D, Gurevich AA, Dvorkin M, Kulikov AS, Lesin VM, Nikolenko SI, Pham S, Prjibelski AD, et al. SPAdes: a new genome assembly algorithm and its applications to single-cell sequencing. J Comput Biol. 2012;19(5):455-77.

12. Vallenet $D$, Belda E, Calteau A, Cruveiller $S$, Engelen $S$, Lajus A, Le Fèvre F, Longin C, Mornico D, Roche D, et al. MicroScope-an integrated microbial resource for the curation and comparative analysis of genomic and metabolic data. Nucleic Acids Res. 2013:41(D1):D636-D47.

13. Edgar RC. Search and clustering orders of magnitude faster than BLAST. Bioinformatics. 2010;26(19):2460-1.

14. Vallenet D, Calteau A, Cruveiller S, Gachet M, Lajus A, Josso A, Mercier J, Renaux A, Rollin J, Rouy Z, et al. MicroScope in 2017: an expanding and evolving integrated resource for community expertise of microbial genomes. Nucleic Acids Res. 2016;45(D1):D517-28.

15. Dischinger J, Josten M, Szekat C, Sahl H-G, Bierbaum G. Production of the novel two-peptide lantibiotic lichenicidin by Bacillus licheniformis DSM 13. PLoS One. 2009;4(8):e6788,

16. Zhou Y, Liang Y, Lynch KH, Dennis JJ, Wishart DS. PHAST: A fast phage search tool. Nucleic Acids Res. 2011;39(suppl_2):W347-W52.

17. Denes T, Vongkamjan K, Ackermann H-W, Moreno Switt Al, Wiedmann M, den Bakker HC. Comparative genomic and morphological analyses of Listeria phages isolated from farm environments. Appl Environ Microbiol 2014; 80(15):4616-4625.

18. Kilcher S, Loessner MJ, Klumpp J. Brochothrix thermosphacta bacteriophages feature heterogeneous and highly mosaic genomes and utilize unique prophage insertion sites. J Bacteriol. 2010;192(20):5441-53.

19. Dorscht J, Klumpp J, Bielmann R, Schmelcher M, Born Y, Zimmer M, Calendar R, Loessner MJ. Comparative genome analysis of Listeria bacteriophages reveals extensive mosaicism, programmed translational frameshifting, and a novel prophage insertion site. J Bacteriol. 2009;191(23):7206-15.

20. Hille F, Richter H, Wong SP, Bratovič M, Ressel S, Charpentier E. The biology of CRISPR-Cas: backward and forward. Cell. 2018;172(6):1239-59.

21. Greer GG, Dilts BD. Control of Brochothrix thermosphacta spoilage of pork adipose tissue using bacteriophages. J Food Prot. 2002;65(5):861-3.
22. Stout E, Klaenhammer T, Barrangou R. CRISPR-Cas technologies and applications in food bacteria. Annu Rev Food Sci Technol. 2017:8(1):413-37.

23. Cheng J, Guffanti AA, Krulwich TA. The chromosomal tetracycline resistance locus of Bacillus subtilis encodes a $\mathrm{Na}+/ \mathrm{H}+$ antiporter that is physiologically important at elevated pH. J Biol Chem. 1994;269(44):27365-71.

24. Zhang H, Lountos G, Bun Ching C, Jiang R. Engineering of glycerol dehydrogenase for improved activity towards 1, 3-butanediol, vol. 88; 2010.

25. Holley RA. Brochothrix. In: Tortorello ML, editor. Encyclopedia of food microbiology. 2nd ed. Oxford: Academic Press; 2014. p. 331-4.

26. Afzal MI, Ariceaga CCG, Boulahya K-A, Jacquot M, Delaunay S, Cailliez-Grimal C. Biosynthesis and role of 3-methylbutanal in cheese by lactic acid bacteria: major metabolic pathways, enzymes involved, and strategies for control. Crit Rev Food Sci Nutr. 2017;57(2):399-406.

27. Casaburi A, Piombino P, Nychas G-J, Villani F, Ercolini D. Bacterial populations and the volatilome associated to meat spoilage. Food Microbiol. 2015;45(0):83-102.

28. Jaffrès $E$, Lalanne V, Macé $S$, Cornet J, Cardinal M, Sérot T, Dousset $X$ Joffraud J-J. Sensory characteristics of spoilage and volatile compounds associated with bacteria isolated from cooked and peeled tropical shrimps using SPME-GC-MS analysis. Int J Food Microbiol. 2011;147(3):195-202.

29. Smit BA, Engels WJM, Wouters JTM, Smit G. Diversity of I-leucine catabolism in various microorganisms involved in dairy fermentations, and identification of the rate-controlling step in the formation of the potent flavour component 3-methylbutanal. Appl Microbiol Biotechnol. 2004;64(3):396-402.

30. Paleologos EK, Savvaidis IN, Kontominas MG. Biogenic amines formation and its relation to microbiological and sensory attributes in ice-stored whole, gutted and filleted Mediterranean Sea bass (Dicentrarchus labrax). Food Microbiol. 2004;21(5):549-57.

31. Nagorska K, Ostrowski A, Hinc K, Holland I, Obuchowski M. Importance of eps genes from Bacillus subtilis in biofilm formation and swarming. J Appl Genet. 2010;51(3):369-81.

32. Woese $C R$, Kandler $\mathrm{O}$, Wheelis ML. Towards a natural system of organisms: proposal for the domains archaea, Bacteria, and Eucarya. Proc Natl Acad Sci. 1990;87(12):4576-9.

33. De Vos P, Garrity GM, Jones D, Krieg NR, Ludwig W, Rainey FA, Schleifer K-H, Whitman WB. Bergey's manual of systematic bacteriology: the firmicutes, vol. 3 Springer. New York; 2009.

34. Gibbons N, Murray R. Proposals concerning the higher taxa of bacteria. Int J Syst Evol Microbiol. 1978;28(1):1-6.

35. Ludwig W, Schleifer K-H, Whitman W. Class I. Bacilli class nov. In: Bergey's manual of systematic bacteriology. De Vos P, Garrity G, Jones D, Krieg N-R Ludwig W, Rainey F-A, Schleifer K-H, Whitman W, editors. vol. 3, 2nd edn. Spinger. New York; 2009. 19-20.

36. Ludwig W, Schleifer K-H, Whitman W. Order II. Lactobacillales Ord. Nov. In: Bergey's manual of systematic bacteriology. De Vos P, Garrity G, Jones D, Krieg N-R, Ludwig W, Rainey F-A, Schleifer K-H, Whitman W, editors. vol. 3, 2nd edn. Springer. New York; 2009. 464

37. Ludwig W, Schleifer K-H, Whitman WB. "Listeriaceae" fam. Nov. In: Bergey's manual of systematic bacteriology. De Vos P, Garrity G, Jones D, Krieg N-R, Ludwig W, Rainey F-A, Schleifer K-H, Whitman W, editors. vol. 3, 2nd edn. Springer. New York; 2009. 244-257.

38. Sneath PHA. Genus II. Brochothrix nov. In: Bergey's manual of systematic bacteriology. De Vos P, Garrity G, Jones D, Krieg N-R, Ludwig W, Rainey F-A, Schleifer K-H, Whitman W, editors. vol. 3, 2nd edn. Springer. New York; 2009. 257-261.

39. Macaskie LE, Sheard AG, Dainty RH, Henderson PJF. Glycerol utilization by Brochothrix thermosphacta. J Appl Bacteriol. 1984;56(1):137-43.

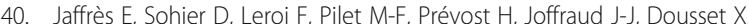
Study of the bacterial ecosystem in tropical cooked and peeled shrimps using a polyphasic approach. Int J Food Microbiol. 2009;131(1):20-9.

41. Ashburner M, Ball CA, Blake JA, Botstein D, Butler H, Cherry JM, Davis AP, Dolinski K, Dwight SS, Eppig JT, et al. Gene ontology: tool for the unification of biology. Nat Genet. 2000;25:25.

42. Katoh K, Misawa K. Kuma K-i, Miyata T. MAFFT: a novel method for rapid multiple sequence alignment based on fast Fourier transform. Nucleic Acids Res. 2002;30(14):3059-66. 